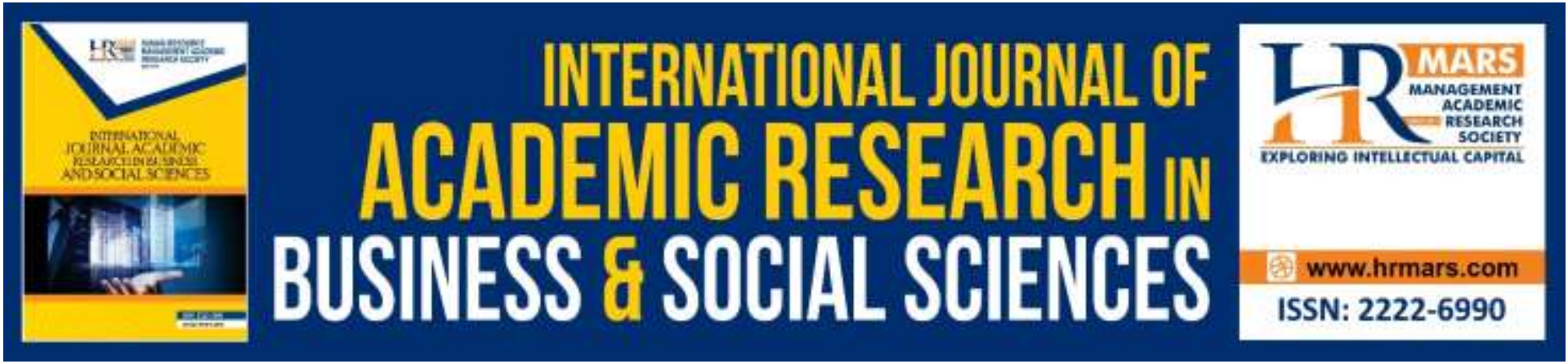

\title{
Forecasting Value at Risk for Malaysian Palm Oil using Monte Carlo Simulation
}

Farah Azaliney Mohd Amin, Nur Aina Syahirah Mohd Sukeri, Norahaslinda Hasbullah and Nurshahira Jamaludin

To Link this Article: http://dx.doi.org/10.6007/IJARBSS/v9-i9/6418

DOI: $10.6007 /$ IJARBSS/v9-i9/6418

Received: 19 July 2019, Revised: 10 August 2019, Accepted: 30 August 2019

Published Online: 24 September 2019

In-Text Citation: (Amin, Sukeri, Hasbullah, \& Jamaludin, 2019)

To Cite this Article: Amin, F. A. M., Sukeri, N. A. S. M., Hasbullah, N., \& Jamaludin, N. (2019). Forecasting Value at Risk for Malaysian Palm Oil using Monte Carlo Simulation. International Journal of Academic Research in Business and Social Sciences, 9(9), 1253-1260.

Copyright: @ 2019 The Author(s)

Published by Human Resource Management Academic Research Society (www.hrmars.com)

This article is published under the Creative Commons Attribution (CC BY 4.0) license. Anyone may reproduce, distribute, translate and create derivative works of this article (for both commercial and non-commercial purposes), subject to full attribution to the original publication and authors. The full terms of this license may be seen at: http://creativecommons.org/licences/by/4.0/legalcode

\section{Vol. 9, No. 9, 2019, Pg. 1253 - 1260}

Full Terms \& Conditions of access and use can be found at http://hrmars.com/index.php/pages/detail/publication-ethics 


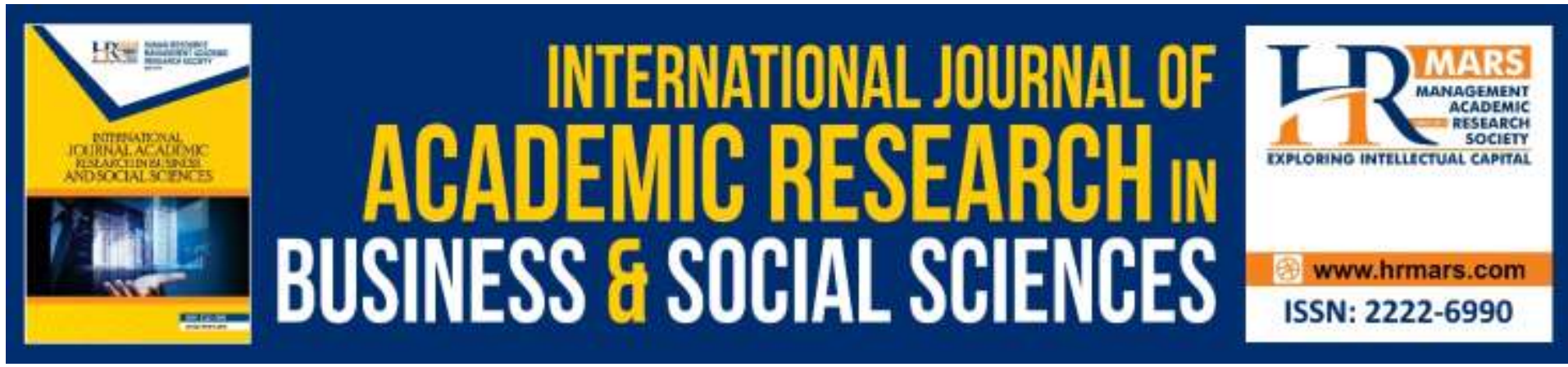

\title{
Forecasting Value at Risk for Malaysian Palm Oil using Monte Carlo Simulation
}

\author{
Farah Azaliney Mohd Amin, Nur Aina Syahirah Mohd Sukeri, \\ Norahaslinda Hasbullah and Nurshahira Jamaludin \\ Faculty of Computer and Mathematical Sciences Universiti Teknologi MARA Cawangan \\ Negeri Sembilan, Kampus Seremban 3, 70300, Seremban,
} Negeri Sembilan, Malaysia

\begin{abstract}
Malaysia is well-known as one of the world's leading exports of its crude palm oil. Thus, palm oil industry is one of the main contributors in Malaysia economic growth. The volatility of crude palm oil (CPO) prices is directly being affected by the demand from its primary importing countries such as European Union, Pakistan, China, US and India. Due to uncertainty in palm oil market prices, therefore it is crucial for this industry to measure and forecast the risk efficiently. The objectives of this study are to forecast the oil prices using Monte Carlo simulation and to compute future Value at Risk (VaR). The result obtained indicate that Monte Carlo provides a flexible and accurate approach for forecasting VaR. Hence, by analyzing the VaR of this volatile oil price environment has very important implications to any market participants especially risk managers and financial institutions when designing risk management strategies within this palm oil industry.
\end{abstract}

Keywords: Value at Risk, Monte Carlo Simulation, Oil Price Volatility, Forecasting.

\section{Introduction}

Currently, Malaysia is second top producer of palm oil in the world after Indonesia. As of 2016, the country's total palm oil production amounted to 2.1 million metric tons with its overall global production accounting for 39\% (Sawe, 2018' Madrid, Ahmed, \& Kumar, 2019). As this crude palm oil industry grows, the palm oil prices is directly affected by the demand from its largest importing countries such as European Union, Pakistan, China, US and India. In addition, the competition between the demands from other vegetables oils, for examples soybean oil, sunflower oil, corn oil also has a significant impact on the fluctuation of palm oil prices. There are significant evidences that oil price volatility have symmetric effects not only to oil market participants but also to governments and society (Sadorsky, 1999; Faff \& Brailsford, 1999; Khalid, Pahi, \& Ahmed, 2016).

Previously, Cabedo and Moya (2003) proposed to estimate Value at Risk for Brent oil prices from January, 1992 to December, 1999 using three approaches: the historical standard approach, the historical simulation with ARMA forecast (HSAF) and variance-covariance based on ARCH models approach. However, this study proposes to forecast VaR for domestic palm 
oil prices by adapting Monte Carlo approach, a simulation technique that will give accurate result if the model is correct and the number of replications is sufficiently large (Seila, Ceric \& Tadikamalla, 2003).

By definition, Value at Risk is a statistical risk measurement method that estimates potential maximum losses in certain periods with certain confidence levels and in a normal market conditions (Best, 1998; Butler, 1999). Hence, VaR is calculated by the following formula

$$
V a R=\alpha \sigma P_{0}
$$

where $\alpha$ is the level of significance in standard normal curve that corresponds to $(1-c)$ if $c$ is the selected confidence level, $\sigma$ denotes the standard deviation and $P_{0}$ denotes the total investment (Jorion, 2001).

Alternatively, VaR can also be obtained directly from the empirical probability distribution functions of profits and losses. VaR can be found by focussing on the left side of the tail end from the probability distribution. Observed that, to determine VaR correspond to $95 \%$ confidence level, the focus will be on the left tail which is the lowest $5 \%$ percentiles in the distribution. The advantages of VaR are this method focuses on the downside risk and independent assumption of the return distribution.

Thus, VaR is a numerical value on the $x$-axis (rate on return) that corresponds to the appropriate value on the $y$-axis (distribution). Figure 1 below illustrates the VaR for two confidence levels when asset returns are normally distributed.

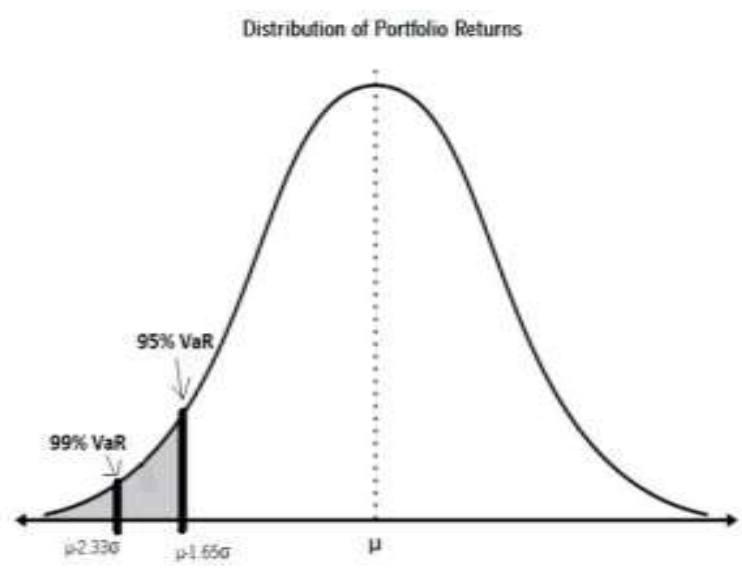

Figure 1. The VaR for $95 \%$ and $99 \%$ confidence level when returns are normally distributed. 


\section{Methodology}

Monte Carlo simulation also known as Monte Carlo sampling technique is a semi-parametric approach. Computing VaR with Monte Carlo Simulation is very similar to Historical Simulation since it makes no specific assumption on the return of the asset. This approach uses the identified distribution pattern of historical data of returns to generate random numbers that will be used to estimate the return of the asset at the end of the analysis horizon (Purwaningsih, Arief, Handayani, Rahmawati \& Mustikasari, 2018).

The following are the steps used to estimate daily Value at Risk (VaR) at $99 \%$ confidence level for palm oil by using Monte Carlo simulation:

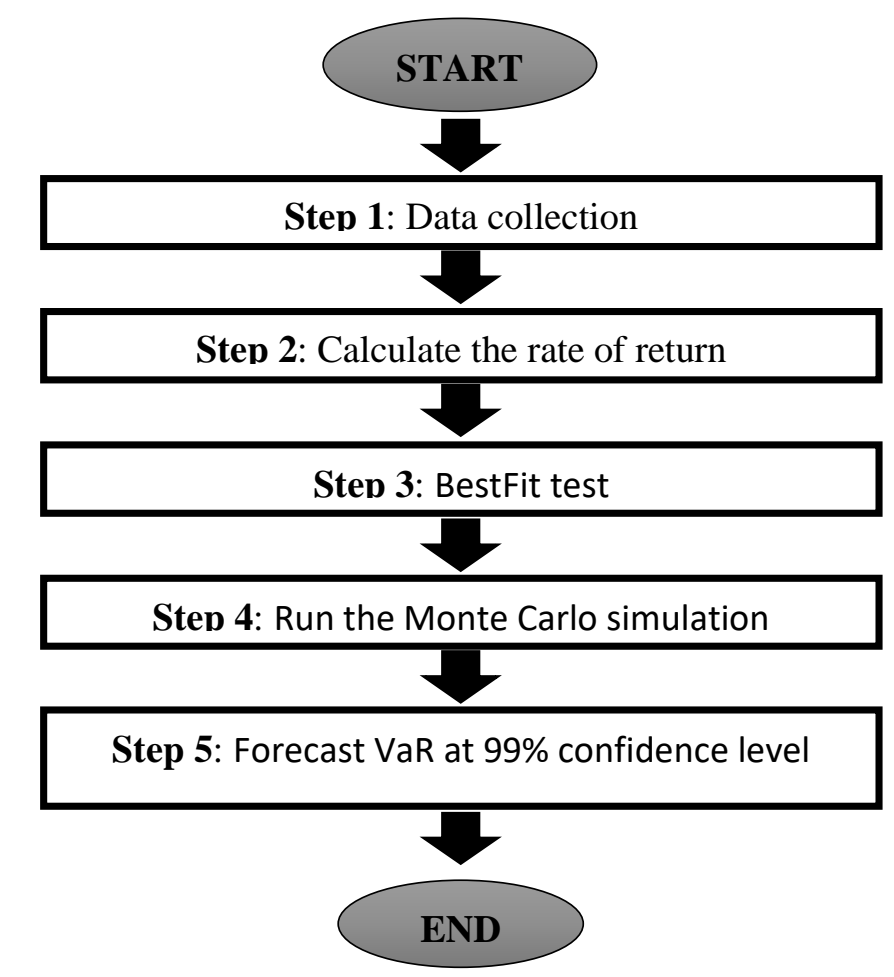

Figure 2. The flowchart to obtain VaR using Monte Carlo simulation.

\section{Step 1: Data Collection.}

The historical data of Malaysia prices for Crude Palm Oil (CPO) was obtained from the official website of Malaysian Palm Oil Board at www.mpob.gov.my. The daily prices was collected for 8 years from January, 2010 until December, 2017. RM is the notation for the Malaysian Ringgit. Observed that, from 2010 to 2012 was considered 'in the sample period' (used to estimate the model parameters) and from 2013 to 2017 was 'out of the sample period' for forecasting purposes.

\section{Step 2: Calculate the Rate of Return}

According to Gruber, Elton, Brown and Goetzmann (1991), the historical return at time- $t, R_{t}$ are calculated using the logarithmic approximation given by the following formula: 


$$
R_{t}=\ln \left[\frac{P_{t}}{P_{t-1}}\right]
$$

(2)

where $P_{t}$ denotes the oil price at time- $t$ and $P_{t-1}$ denotes the oil price at time $t-1$.

\section{Step 3: Best Fit Test.}

In this step, the function BestFit test in the @RISK software is performed to the historical return 'in the sample period' to identified distribution pattern that best fit the data. Before the simulation, there are two input parameters: mean $(\mu)$ and standard deviation $(\sigma)$ need to be determine since BestFit test identified that the past data follows normal distribution.

\section{Step 3: Run the Monte Carlo Simulation}

The simulation is performed using @RISK add-in software in Microsoft Excel. As an example, Figure 3 below illustrates a Monte Carlo simulation with 10,000 observations for future palm oil prices returns in 2016. With the future value of palm oil prices, this study is able to determine the future value of VaR for the 'out of the sample period' (2013-2017).

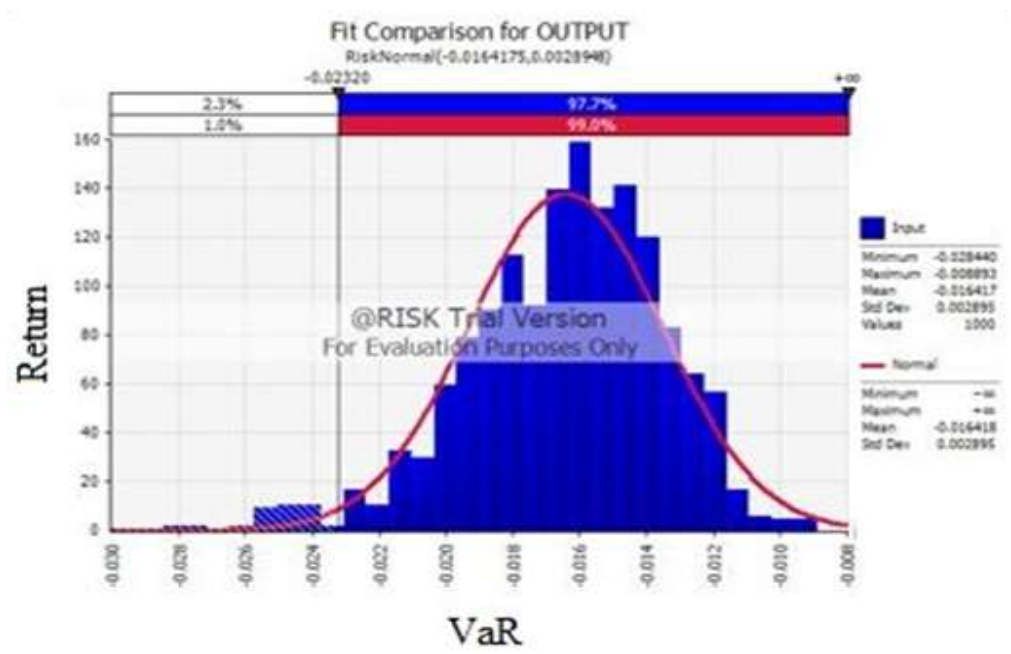

Figure 3. Histogram using Monte Carlo simulation in 2016

Observed that, the histogram using 10,000 random outcomes resembles the normal distribution with mean -0.01642 and standard deviation 0.002895 . Note also, the result of VaR using Monte Carlo is different each time you run the simulation. This is because Monte Carlo simulation is a stochastic process that generate random numbers based on the input data. Hence, it produces distribution that have similar characteristics for the estimations of VaR (Abad, Benito \& Lopez, 2014).

\section{Step 4: Forecast VaR at $\mathbf{9 9 \%}$ confidence level}

VaR is the percentiles obtained from the statistical distribution of simulated future values of oil price returns associated with the desired likelihood level. Thus, VaR is the statistical value observed on the $x$-axis for a given probability on the $y$-axis. Observed that, to determine VaR correspond to $99 \%$ confidence level, the focus will be on the left tail which is the lowest $1 \%$ 
percentiles in the distribution. For example in Figure 3, $\mathrm{VaR}$ at the $99 \%$ confidence level is 0.0232. Notice that, we drop the minus sign because VaR is referred to as a loss.

\section{Validation}

The accuracy of VaR estimates using Monte Carlo simulation approach is then being verified using Mean Absolute Percentage Error (MAPE). MAPE usually express accuracy as a percentage and is calculated as follows:

$$
\text { MAPE }=\left[\frac{1}{n} \sum_{i=1}^{n} \frac{\left|a_{i}-p_{i}\right|}{\left|a_{i}\right|}\right] \mathrm{X} 100
$$

where $n$ equal to the total number of unit trust fund involved, $a_{i}$ and $p_{i}$ are actual and predicted values, respectively.

The scale of the judgement of forecasting the accuracy by using MAPE is illustrated in Table 2 below. The approach with a lower MAPE is expected to produce better results.

Table 1. Scale of Accuracy using MAPE

\begin{tabular}{cl}
\hline MAPE & Accuracy \\
\hline$<10 \%$ & Highly accurate \\
$11 \%-20 \%$ & Good forecast \\
$21 \%-50 \%$ & Reasonable forecast \\
$>51 \%$ & Inaccurate forecast \\
\hline
\end{tabular}

\section{Results and Discussions}

Figures 4 below shows a graphical summary of future VaR using Monte Carlo simulation and the actual VaR for each consecutive year from 2013 until 2017.

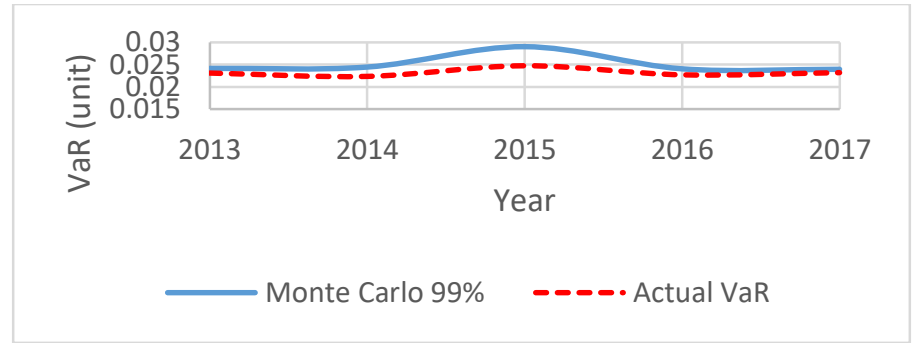

Figure 4. Comparison between Historical Simulation and actual VaR

As shown, future VaR using Monte Carlo simulation is slightly higher than actual VaR for the five-year observed in the 'out of sample period'. However, we observed the same trends between future oil price returns and actual VaR where the lowest observation and the highest VaR was on 2014 and 2015, respectively. These numbers provide risk managers with reliable information about the expected losses that will occur in the near future under normal market condition. To further evaluate the performances of Monte Carlo simulation and verify the accuracy of these estimates, the Mean Absolute Percentage Error (MAPE) is calculated using Equation (3). Comparatively, although it looks like Monte Carlo simulation 
overestimates market risk, result found that the average MAPE for the proposed approach is $5.23 \%$ only. Hence, Monte Carlo simulation approach is considered highly accurate in forecasting VaR for palm oil prices between 2013 until 2017 since the average MAPE value are less than $10 \%$ using Table 1 above.

\section{Conclusion}

In this study, Value at Risk concept has successfully been apply to summarize the worst loss over a target horizon with a given level of confidence for Malaysia's crude palm oil prices. Apart from being able to measure the market risk efficiently, the other advantages found in this study are VaR using Monte Carlo simulation approach has also successfully estimate the future downside risk within this palm oil industry. Results of this study revealed that Monte Carlo simulation is highly accurate method to forecast daily $\mathrm{VaR}$ at $99 \%$ confidence level during the five-year period observed. Note that, the greater the VaR consequently indicate the greater the risk anticipated and vice versa. Hence, by observing the future trend of this oil prices movement will certainly assist any market participants especially investors or decision-makers when designing risk management strategies.

\section{Corresponding Author}

Farah Azaliney Mohd Amin

Department of Mathematics

Faculty of Computer and Mathematical Sciences

Universiti Teknologi MARA Cawangan Negeri Sembilan,

Kampus Seremban 3, 70300, Seremban,

Negeri Sembilan, Malaysia

Email: farah525@uitm.edu.my

\section{References}

Abad, P., Benito, S., \& Lopez, C. (2014). A Comprehensive Review of Value at Risk Methodologies. The Spanish Review of Financial Economics, 12, 15-32.

Best, P. (1998). Implementing Value at Risk. West Sussex: John Wiley \& Sons Inc.

Butler, C. (1999). Mastering Value at Risk : A Step-by-step Guide to Understanding and Applying VaR. Great Britain: Prentice Hall.

Faff, R. W., Brailsford, T. J. (1999). Oil price risk and the Australian stock market. J. Energ. Finance Dev. 4, 69-87.

Gruber, M. J., Elton, E. J., Brown, S. J., \& Goetzmann, W. N. (1991). Modern Portfolio Theory and Investment Analysis. Singapore: John Wiley \& Sons, Inc.

Jorion, P. (2001). Value at Risk: The New Benchmark for Managing Financial Risk. Business and Economics, 1-24.

Khalid, N., Pahi, M. H., \& Ahmed, U. (2016). Loosing your best talent: Can leadership retain employees? The dilemma of the banking sector of Hyderabad Sindh, Pakistan: A mediation investigation. International Review of Management and Marketing, 6(3), 608-616.

Madrid, D., Ahmed, U., \& Kumar, R. (2019). Examining the Impact of Classroom Environment on Entrepreneurship Education: Case of a Private University in Bahrain. Journal of Entrepreneurship Education, 22(1), 1-8. 
Purwaningsih, R., Arief, M., Handayani, N. U., Rahmawati, D., \& Mustikasari, A. (2018). Market Risk Assessment on Poultry Industry using Monte Carlo simulation. IOP Conference Series: Materials Science and Engineering, 403, 012044.

Sadorsky, P. (1999). Oil price shocks and stock market activity. Energ. Econ. 21, 449-469.

Sawe, B. E. (2018). Top Palm Oil Producing Countries In The World. Retrieved from https://www.worldatlas.com/articles/top-palm-oil-producing-countries-in-theworld.html 